\title{
STS 2019 Workforce Report: Ad Hoc Analysis of Women in Cardiothoracic Surgery
}

Running Head: Review of Women in CT Surgery

DuyKhanh P Ceppa ${ }^{1}$, John S Ikonomidis ${ }^{2}$, Lava R Timsina ${ }^{3}$, Natalie Boden ${ }^{4}$, Lauren C Kane ${ }^{5}$, Jessica S Donington ${ }^{6}$

${ }^{1}$ Division of Cardiothoracic Surgery, ${ }^{3}$ Department of Surgery, Indiana University School of Medicine, Indianapolis, Indiana; ${ }^{2}$ Division of Cardiothoracic Surgery, University of North Carolina at Chapel Hill, Chapel Hill, North Carolina; ${ }^{4}$ Society of Thoracic Surgeons, Chicago, Illinois; ${ }^{5}$ Division of Cardiothoracic Surgery, University of Central Florida, Orlando, Florida; ${ }^{6}$ Department of Cardiothoracic Surgery, University of Chicago, Chicago, Illinois

\section{Corresponding author:}

DuyKhanh P Ceppa, MD

Division of Cardiothoracic Surgery, Department of Surgery

Indiana University School of Medicine

545 Barnhill Drive, EH 215

Indianapolis, IN 46228

dpceppa@iupui.edu

Word count: 1494

This is the author's manuscript of the article published in final edited form as:

Ceppa, D. P., Ikonomidis, J. S., Timsina, L. R., Boden, N., Kane, L. C., \& Donington, J. S. (2021). STS 2019 Workforce Report: Ad Hoc Analysis of Women in Cardiothoracic Surgery. The Annals of Thoracic Surgery, 111(2), 383-385. https://doi.org/10.1016/j.athoracsur.2020.07.071 
The Society of Thoracic Surgeons (STS) is the world's largest cardiothoracic surgical organization, representing more than 7500 surgeons, researchers and allied health care professionals worldwide. In response to the ever-changing working environment of cardiothoracic surgery, the STS conducts a workforce survey approximately every five years. The 2019 Practice Survey was performed in the fall of 2019, the results of which were discussed at the STS 2020 annual meeting and were published by lkonomidis, et al. ${ }^{1}$ Since women remain an extremely small subset of the cardiothoracic workforce the Women in Thoracic Surgery (WTS) in conjunction with the STS, reviewed the 2019 workforce survey results with a focus on female respondents.

\section{METHODS}

The STS workforce survey was administered as previously described. ${ }^{1}$ Comparisons between male and female respondents were performed with bivariate Pearson's chi-square or Fishers exact tests for categorical variables as appropriate. The outcome variables examined in the study were ordinal in scale. Multivariable ordinal probit regressions with robust standard errors were done using age, year of entering CT practice, years of post MD training, practice settings, full-time equivalent (FTE) and surgery subspecialty to examine the gender differences in these outcomes. $^{2}$ All analyses were done at 0.05 level of significance using Stata SE/14.2.

\section{RESULTS}

Demographics, training, and debt

Of 3834 STS surgeon members who received the 2019 practice survey, 1069 (27.9\%) responded. ${ }^{1}$ Of the respondents, 1020 indicated gender and of these respondents $83(8.1 \%)$ 
reported being female. The mean age of female surgeons was 49 years, with $46 \%$ of female surgeons having graduated from medical school 2000 or after $(43.4 \% 2000-2009,2.4 \%$ 2010-2014). Only $2.5 \%$ had six years or less of training and $35.8 \%$ reported 10 years post-MD training prior to entering practice. With regards to additional professional degrees, $2.4 \%, 6 \%$, and 9.6\% women surgeons stated they also had an $\mathrm{PhD}, \mathrm{MBA}$, or $\mathrm{MPH}$; no female respondents also had a JD. Nine percent of female respondents are board-certified in critical care. Seventy-four percent of women surgeons reported having some educational debt. Of those reporting an educational debt, $23 \%$ had a debt $\$ 49,999$ or less, $8.2 \%$ had $\$ 50,000-\$ 74,999$ in debt, $6.6 \%$ had $\$ 75,000-\$ 99,999$ in debt, $19.7 \%$ had $\$ 100,000-149,999$ in debt, and $42.6 \%$ had $>\$ 150,000$ in debt before entering practice.

\section{Practice and employment}

The majority (61.4\%) of women cardiothoracic surgeons entered practice 2005 or after; $15.7 \%$, $10.8 \%$, and $12 \%$ entered practice $2000-2004,1995-1999$, and before 1995 , respectively. No female respondent entered practice prior to 1975 . Four (4.8\%) of the female respondents were retired. Of those who were currently working, 1.3\% indicated the intention to retire between $50-54$ years, $8.9 \%$ between $55-59$ years, $17.7 \%$ between $60-64$ years, $43 \%$ between $65-69$ years, and $15.2 \% 70$ years or greater; $13.9 \%$ were undecided regarding age of retirement. Ninety-two percent of women cardiothoracic surgeons reported working full time. These respondents reported working in an academic practice (41), private practice (21), research (1), a purely administrative (2) or other (11) position. No female respondent reported working part time in a clinical practice; 4 (5.1\%), $11(14.1 \%)$, and $1(1.3 \%)$ women reported having at least a part time role in clinical academics, research, or administration. Thirty-seven percent, $27.7 \%, 10.8 \%$ and $15.7 \%$ of female surgeons reported a thoracic, adult cardiac, congenital, or mixed practice, respectively (8.4\% other). Most (55.7\%) female surgeons worked at an urban hospital; $16.5 \%$ in a suburban and $7.6 \%$ in a rural setting. Fifty-seven percent of female respondents reported 
working at one hospital while $32.9 \%$ and $8.9 \%$ reported working at $2-3$ and $\geq 4$ hospitals. The majority $(74.4 \%)$ reported working between 51 to 80 hours a week (24.4\% 51-50 hours/week, $30.8 \% 61-70$ hours/week, $19.2 \% 71-80$ hours/week) while $14 \%$ reported working 50 hours or less and $11.5 \%$ reported working greater than 80 hours per week.

Income

Most (86.5\%) female cardiothoracic surgeons reported an income between $\$ 200,000$ and $\$ 799,999$. The most commonly reported income category was $\$ 200,000-\$ 399,999(39.2 \%)$; $9.5 \%$ and $4 \%$ of women reported an income of $<\$ 200,000$ and $>\$ 800,000$. Sixty percent of women reported being satisfied with their income, with $25 \%$ and $15.2 \%$ of women being "somewhat satisfied and "not at all satisfied."

\section{Overall satisfaction}

Eighty-one percent of female respondents reported being satisfied (39.2\%), very satisfied $(36.7 \%)$ or extremely satisfied $(5.1 \%)$ with their current career. However, $66.7 \%$ of women reported having burnout symptoms. Seventy percent of women would encourage a family member to study medicine; $56.8 \%$ would encourage a family member to pursue a career in cardiothoracic surgery; $23.5 \%$ discouraged a medical student from pursuing a career in cardiothoracic surgery.

\section{Female-male comparison}

In comparison to male respondents, female cardiothoracic surgeons did not differ with respect to number of years in training, having an MBA, PhD or JD, or dual board certification in critical care. Men and women did not differ in practice location, number of hospitals they practiced at nor number of hours worked per week. They were equally as likely to be in an academic practice and to be working full time. 
Not surprisingly, at the time of the survey women cardiothoracic surgeons were more likely to be younger $(p<0.001)$, to have entered practice more recently $(p=0.004)$, and to have a larger educational debt at the time of entering practice $(p=0.006)$. Female surgeons were slightly more likely to have an MPH $(9.6 \%$ vs. $2.4 \%, p=0.002)$. Women cardiothoracic surgeons were more likely to have a practice in general thoracic surgery while men were more likely to have a mixed practice $(p=0.002)$. Female surgeons reported an intent to retire at an earlier age than male surgeons $(p=0.008)$. However, when factoring in for age, subspecialty and type of practice (academic versus private) in the multivariable regression this difference in intended age of retirement between genders was no longer significant $(p=0.75)$.

With regards to salary, a gender difference in income categories was noted. After factoring in age, year entering practice, subspecialty and type of practice (academic versus private) in the multivariable model women were 3,14 , and 14 percentage points more likely than men to report an income of $<\$ 200,000, \$ 200-400,000$, and $\$ 400-600,000$, respectively $(p<0.001)$. Women were 5 percentage points less likely than men to report an income of $>\$ 600-800,000$ and 26 percentage points less likely to report an income of $>\$ 800,000(p<0.001)$.

While women cardiothoracic surgeons, overall, reported being satisfied with their career they were less likely to report being "extremely" satisfied and more likely to be "somewhat satisfied" $(p=0.013)$, which also held true in multivariable analysis (Coeff $=-0.25[-0.47,-0.30]$, $\mathrm{p}=0.026)$. Women trended toward being more likely to report burn out then men $(66.7 \% \mathrm{vs}$. $55 \%, p=0.05)$. However, they were equally as likely as men to encourage a family member to pursue a career in medicine or cardiothoracic surgery, and as likely to encourage a medical student to pursue a career in cardiothoracic surgery.

\section{COMMENT}


Since the first publication in 1974, the STS Task Force on Practice and Access has used the practice survey to assess and address cardiothoracic surgery manpower and clinical practice issues. To date, analyses on women in cardiothoracic surgery have been limited. ${ }^{3-5}$ While an update on the status of women in cardiothoracic surgery is ongoing (personal communication) we reviewed the 2019 STS practice survey data with a woman's perspective.

Women cardiothoracic surgeons are increasing in number. However, they only constituted $8.4 \%$ of the practice survey's respondents and $<5 \%$ of ABTS-certified cardiothoracic surgeons. ${ }^{6}$ As a discipline, with an aging patient population and a significant cohort of retiring surgeons, we are predicted to have a shortage of surgeons. ${ }^{7}$ Given that $50 \%$ of medical school graduates are female, successful recruitment of women is imperative to keeping up with this future work force deficit. However, our ad hoc analysis demonstrated that the salaries between men and women cardiothoracic surgeons is discrepant, even after accounting for age, year entering practice, subspecialty, and academic versus private practice. This finding of discrepant salaries between genders in cardiothoracic surgery has also been previously described. ${ }^{4}$ While there are multiple factors that influence recruitment, equitable treatment and fostering an environment free of gender bias is critical to recruiting women into any medical specialty. ${ }^{8,9}$

It is encouraging that women cardiothoracic surgeons find satisfaction in their careers and are equally as likely as male surgeons to recommend a career in our discipline to a family member or medical student. It would be more ideal, however, if women were equally as likely as men to find a career in CT "extremely satisfying."

Our study has recognized limitations, which are also acknowledged in the 2019 STS work force report. ${ }^{1}$ Additionally, the 2019 STS work force survey was not specifically designed for a complete and thorough comparison of female and male cardiothoracic surgeons. As previously mentioned, a more in-depth analysis of the status of ABTS-certified female cardiothoracic 
surgeons and unique factors that they may face is ongoing. Finally, the issue of salary is multifactorial and this analysis did not account for relative value units (RVUs), geographic variations or seniority and academic rank. However, this ad hoc analysis highlights a few of the issues with regards to gender disparities within our specialty that require attention for future generations.

Acknowledgment: The authors wish to thank the STS Executive Committee and STS Leadership for their support of this work. 


\section{References}

1. Ikonomidis JS, Boden N, Atluri P. The Society of Thoracic Surgeons Thoracic Surgery Practice and Access Task Force-2019 Workforce Report. Ann Thorac Surg. 2020.

2. Long JSaF, J. (2006) Regression Models for Categorical and Limited Dependent Variables Using Stata, Second Edition. College Station, Texas: Stata Press.

3. Dresler CM, Padgett DL, MacKinnon SE, Patterson GA. Experiences of women in cardiothoracic surgery. A gender comparison. Arch Surg. 1996;131(11):1128-1134; discussion 1135.

4. Roberts SR, Kells AF, Cosgrove DM, 3rd. Collective contributions of women to cardiothoracic surgery: a perspective review. Ann Thorac Surg. 2001;71(2 Suppl):S19-21.

5. Donington JS, Litle VR, Sesti J, Colson YL. The WTS report on the current status of women in cardiothoracic surgery. Ann Thorac Surg. 2012;94(2):452-458; discussion 458-459.

6. Antonoff MB, David EA, Donington JS, et al. Women in Thoracic Surgery: 30 Years of History. Ann Thorac Surg. 2016;101(1):399-409.

7. Moffatt-Bruce S, Crestanello J, Way DP, Williams TE, Jr. Providing cardiothoracic services in 2035: Signs of trouble ahead. J Thorac Cardiovasc Surg. 2018;155(2):824-829.

8. Backhus LM, Lui NS, Cooke DT, Bush EL, Enumah Z, Higgins R. Unconscious Bias: Addressing the Hidden Impact on Surgical Education. Thorac Surg Clin. 2019;29(3):259-267.

9. Ceppa DP, Dolejs SC, Boden N, et al. Gender Bias and Its Negative Impact on Cardiothoracic Surgery. Ann Thorac Surg. 2020;109(1):14-17. 
Tables 1. Practice mix-percent of men or women in each subspecialty.

\begin{tabular}{l|cc|c} 
& \multicolumn{2}{|c|}{$\begin{array}{c}\text { Specialty by Gender } \\
\text { Fale (n=937) }\end{array}$} & $\begin{array}{c}\text { Female (n=83) } \\
\text { specialty }\end{array}$ \\
\hline Adult cardiac & $28.3 \%$ & $27.7 \%$ & $8.0 \%$ \\
Congenital & $7.8 \%$ & $10.8 \%$ & $11.0 \%$ \\
General Thoracic & $20.7 \%$ & $37.4 \%$ & $13.8 \%$ \\
Mixed Practice & $31.7 \%$ & $15.7 \%$ & $4.2 \%$ \\
Other & $11.5 \%$ & $8.4 \%$ & $6.1 \%$
\end{tabular}




\section{Figure Legend}

Figure 1. Career satisfaction by gender on a Likert-like scale. 


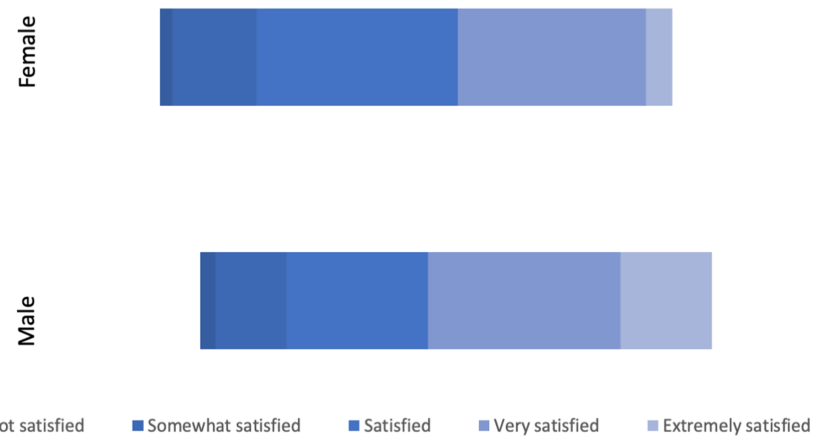

